\title{
Acute Coronary Syndromes in Patients with Hematological Disorders
}

\author{
István Benedek ${ }^{1,2}$, Erzsébet Lázár ${ }^{1,2}$, Johanna Sándor-Kéri ${ }^{1,2}$, Szilárd Bíró ${ }^{1,2}$, Szende Jakab ${ }^{1,2}$, \\ István Benedek Jr. ${ }^{1,2}$ \\ ${ }^{1}$ University of Medicine and Pharmacy, Tîrgu Mureș, Romania \\ ${ }^{2}$ Clinic of Hematology and Bone Marrow Transplantation Unit, Tîrgu Mureș, Romania
}

\begin{abstract}
Hematological conditions can lead to serious disturbances in blood rheology, being frequently associated with increased systemic inflammation and increased risk of bleeding. The imbalance between coagulation and thrombolytic factors in patients with acute coronary syndromes may lead to undesirable outcomes, and the success of emergency coronary angioplasty or by-pass grafting may be altered by increased bleeding in coagulopathies such as hemophilia. This paper intends to review the present knowledge in the field of acute coronary syndromes in subjects with hematological and onco-hematological disorders such as thrombotic thrombocytopenic purpura, immune thrombocytopenic purpura, von Willebrand disease, hemophilia, polycythemia vera, erythrocyte disorders, myelodysplastic syndrome, leukemia, lymphoma or myeloma.
\end{abstract}

Keywords: myocardial infarction, thrombosis, platelets

\section{ARTICLE HISTORY}

Received: 4 March, 2016

Accepted: 20 June, 2016

\section{CORRESPONDENCE}

\section{Erzsébet Lázár}

Str. Revoluției nr. 35

540042 Tîrgu Mureș, Romania

Tel: +40 265218739

E-mail: erzsebetlazarbenedek@

gmail.com

\section{INTRODUCTION}

Hematological conditions can lead to serious disturbance in the blood rheology resulting at times in a pro-thrombotic status. The diseases in this group are frequently associated with an increased systemic inflammation and an increased risk of bleeding, resulting in an imbalance between coagulation and thrombolytic factors. Various changes in blood homeostasis associated with the occurrence of an acute coronary syndrome may lead to undesirable outcomes and the success of emergency coronary angioplasty or bypass grafting may be altered by increased bleeding in coagulopathies such as hemophilia.

This paper intends to review present knowledge in the field of acute coronary syndromes in subjects with hematological and onco-hematological disorders. 


\section{THE LINK BETWEEN ACUTE CORONARY SYNDROMES, PLATELET DISORDERS AND COAGULOPATHIES}

\section{ACUTE CORONARY SYNDROMES IN PATIENTS WITH THROMBOCYTOPENIA AND THROMBOTIC THROMBOCYTOPENIC PURPURA}

Platelets have a significant role in the development of acute coronary thrombosis that overlaps a ruptured atherosclerotic plaque. ${ }^{1}$

A large, multi-institutional cohort study (2013), which included 4,032 patients from the 2001-2010 Nationwide Inpatient Sample database with thrombotic thrombocytopenic purpura (TTP) who underwent plasmapheresis (mean age 47.5 years, $67.7 \%$ female), showed that despite having been treated for TTP, 5.7\% of patients developed an acute coronary syndrome (ACS) during hospitalization. The predictors of acute myocardial infarction (AMI) included age, tobacco use, known coronary artery disease (CAD), and congestive heart failure (CHF). ${ }^{2}$

Gandhi et al. (2010), reporting on 27 females, mean age $44 \pm 18$ years, showed that $21 \%(n=8)$ of the patients developed new Q-wave AMI during their hospital stay. ${ }^{3}$ Similarly, Wahla et al. recorded that between 1996 and 2005, $15.3 \%(n=13)$ of the patients admitted for TTP $(n=85)$, presented an ACS during hospitalization. ${ }^{4}$

\section{CAN ACUTE MYOCARDIAL INFARCTION REPRESENT A COMPLICATION OF IMMUNE THROMBOCYTOPENIC PURPURA?}

Immune thrombocytopenic purpura (ITP), leading to a low platelet count, is rarely associated with ACS. Despite the increased risk of bleeding, patients with ITP also have an increased rate of atherosclerosis and thrombosis. ${ }^{5}$

Being a rare occurrence, clinical studies on ACS in ITP patients are scarce. Torbey et al. (2013) reported two patients, aged 55 and 61 years, with ACS and ITP. ${ }^{6}$

A review published in 2011, comparing the results of coronary artery bypass grafting (CABG) versus primary coronary intervention (PCI) in subjects with ITP found 32 patients with ITP who underwent CABG, mean age $63 \pm 10$ years, and 15 cases of ITP with PCI, mean age $62 \pm 16$ years. Their conclusion was that both revascularization methods are safe and feasible and that the cessation of antiplatelet therapy should be commenced when the platelet count is less than $20,000 / \mu \mathrm{L} .{ }^{7}$

A report (2016) of 14 AMI patients with concomitant immune thrombocytopenic purpura, nine men and five women, mean age $56 \pm 17$ years, highlighted the option of coronary balloon angioplasty for revascularization in this group, in order to reduce the duration of dual antiplatelet treatment and the risk of bleeding. ${ }^{8}$

Possible etiologies of enhanced thrombosis in ITP include antibody reaction to platelets and release of platelet microparticles, the release of larger and younger platelets, splenectomy, several treatments such as steroids or danazol, as well as autoantibodies directed against antigens that are presentd both on the thrombocyte and the endothelial surface, and anti-phospholipid antibodies (aPL). ${ }^{9}$

\section{ACS IN PATIENTS WITH VON WILLEBRAND DISEASE}

The von Willebrand factor (vWF) holds a vital place in the coagulation cascade. An elevated level of vWF leads to an augmented risk of coronary artery disease. In ST-elevation MI (STEMI) the level of vWF increases up to 1.5-2fold in the first 24 hours and peaks at $48-72$ hours. ${ }^{10}$

The ATHEROREMO-IVUS study (conducted between 2008 and 2011) showed that a high coronary plaque burden was correlated with elevated von Willebrand factor antigen levels ( $\mathrm{p}=0.027$ ) in subjects with stabile angina pectoris, but not in patients with ACS. In patients with acute ACS, high vWF levels were predictive for adverse cardiovascular events and mortality rates during the 1-year follow-up. ${ }^{11}$

Lim et al. analyzed the rate of ACS in patients with von Willebrand disease, describing ten cases of ACS. Their results showed that in subjects with mild congenital hemorrhagic disease, the intervention was not complicated by severe hemorrhagic events even if they had not received factor concentrates before the coronarography. The administration of double antiplatelet treatment for a short amount of time was tolerated relatively well. Patients who received aspirin for a long-term, had shown mild bleeding complications, but these cases require close follow-up. ${ }^{12}$

In a case report (2013) on type 1 von Willebrand disease, with $25 \%$ factor VIII activity, a percutaneous coronary intervention was performed with bare-metal stent implantation and dual-antiplatelet therapy was administered for two weeks, without any bleeding complications. ${ }^{13}$

Mohammad et al. (2014) published the case of an individual diagnosed with type 2 von Willebrand disorder and a history of severe bleeding, who presented with a nonST elevation MI (NSTEMI). The patient needed multiple stent implantations to minimize restenosis, including the implantation of drug eluting stents at the level of the left anterior descending artery, first diagonal (D1) artery and proximal part of the first obtuse marginal (OM) artery. 
Drug therapy included oral aspirin and clopidogrel, and no periprocedural bleeding was reported..$^{14}$

A presentation of five cases indicated that anticoagulant therapy can be safely administered by giving factor protection when vWF activity levels are maintained at 30\%. Martin et al. (2016) suggested the usage of high-intensity anticoagulation for a minimal duration associated with clotting factor administration. This study recommended keeping the vWF activity at a level higher than 50\% before the procedure. ${ }^{15}$

\section{HEMOPHILIA AND ACS}

The majority of studies regarding ACS in hemophilic patients advocate a less hostile approach and additional care and treatment. Subjects with inherited hemorrhagic pathologies are predisposed to higher bleeding rates; therefore, thrombolysis for MI is unjustified in such cases. Anticoagulant treatment is to be initiated with an intravenous injection of unfractionated heparin, followed by continuous administration for 2-3 days in association with double antiplatelet medication (aspirin, clopidogrel). Daily smalldose acetylsalicylic acid (ASA) must be administered for an indefinite time, and clopidogrel must be ceased after 4 weeks from its introduction in the therapeutic plan.

In case of STEMI in patients with hemophilia, primary PCI is recommended. Bare-metal stents are preferred to drug-eluting stents due to the fact that they require a smaller amount of time for two antiplatelet drugs, usually one month, and consequently, a shorter time of rigorous prophylaxis maintaining the factor concentration at $30 \%$ or more. Initial management of STEMI with glycoprotein IIb/IIIa inhibitors is not feasible due to an enhanced bleeding risk. In hemophilic patients, the activity of the missing factor should be at least $80 \%$ at the moment of heparin administration and coronary intervention. ${ }^{16-18}$

The ARCHER study (2015) analyzed the frequency of cardiovascular disease in hemophilic patients, and reported an incidence of 14/1000 patients for any CVD event, 8.2/1000 patients for CAD and 3.5/1000 patients for MI (NSTEMI and STEMI). The majority of the CVD events were treated with revascularization (12 procedures -3 CABG and 9 PCI). Interventional revascularization was performed with bare-metal stents in six cases and with drug-eluting stents in one case. All patients who underwent coronary angioplasty with stent implantation were treated with dual antiplatelet therapy for 1-3 months, followed by longer term aspirin therapy. Furthermore, prophylactic coagulating factor concentrate was administered to all patients prior to the coronary intervention, and preoperatively for those who had undergone CABG surgery. ${ }^{19}$

van de Putte et al. (2012), analyzing 408 patients with hemophilia, of which 204 were considered severe and 204 non-severe, identified a $2.5 \%$ rate of $\mathrm{MI}$ in the disease group, versus $4.8 \%$ in age-matched controls. ${ }^{20}$

Fogarty et al. (2015) sought to determine patient characteristics, cardiovascular risk factors, coagulopathy features, as well as the hemostasis protocol used in case of patients with ACS and hemophilia, in a 10-year survey. From the 2,000 hemophiliacs, 20 had presented an ACS. They concluded that ACS occurs in younger hemophilia patients who have associated cardiovascular risk factors, and that secondary cardiovascular prevention and revascularization therapies followed by dual antiplatelet therapy are feasible therapeutic approaches in selected cases. $^{21}$

\section{ACS IN SUBJECTS WITH POLYCYTHEMIA VERA AND ESSENTIAL THROMBOCYTHEMIA}

Polycythemia vera (PV) is defined as the excessive proliferation of red blood cells, leading to hyperviscosity and increased risk of thrombosis. In patients with PV, the main causes of mortality are acute myocardial infarction and heart failure.

Essential thrombocythemia (ET) is manifested clinically as the excessive production of platelets. These platelets are dysfunctional, leading to an increased risk of bleeding and thrombosis. Thromboembolic events are frequent and are usually represented by deep vein thrombosis and pulmonary embolism. AMI is unusual in this case. ${ }^{22}$

According to the ECLAP study, the prevention of acute coronary syndromes in PV patients consists of low-dose aspirin for the prevention of thromboembolic events that reduces the risk of nonfatal myocardial infarction by $30 \%{ }^{23}$

Cytoreductive therapy aims to reduce thromboembolic risk by using phlebotomy or hydroxyurea and is recommended for all patients in order to achieve the optimal control of blood cell counts. ${ }^{24}$

In patients with PV and ET with acute myocardial infarction, percutaneous reperfusion followed by aggressive antithrombotic treatment is recommended in association with cytoreductive medication. Cytoreductive treatment is linked to an important decrease in the rate of thrombotic complications. Hydroxyurea is suggested as first-line treatment and anagrelide is recommended as a secondline therapy due to its minimal leukemogenic effects in young patients. ${ }^{25}$ 
De Stefano et al. studied the recurrence rate of thrombotic events in patients with PV/TH who had previously suffered arterial or venous thrombosis or both, in a retrospective multicenter study that included 497 patients. Their results showed a $33.6 \%$ thrombosis recurrence rate and pointed out an elevated leukocyte count as a risk factor for recurrence in patients older than 60 years. This study also showed that the best preventive strategy in these cases is represented by cytoreductive therapy associated with antiplatelet drugs and anticoagulants. ${ }^{26}$

A meta-analysis on 17 studies that included 2,905 patients showed that the presence of the JAK2 V617F mutation was associated with an increased risk of both venous and arterial thrombosis in patients with essential thrombocythemia. ${ }^{27}$

Similar results were published in a retrospective multicenter study involving 239 patients with ET. In that study, previous thrombotic history and the JAK2 V617F mutation were connected to an increased 10-year cumulative rate of thrombohemorrhagic events. ${ }^{28}$

A retrospective study (2016) of 263 patients analyzed the rate of acute myocardial infarction in patients with ET or PV. During follow-up, 10 cases of STEMI and 4 cases of NSTEMI were described, and the majority of the acute coronary events had occurred during the first year after diagnosis. ${ }^{29}$

\section{ANEMIA, ERYTHROCYTE DISORDERS AND AMI}

\section{AUTOIMMUNE HEMOLYTIC ANEMIA COMPLICATED WITH ACUTE MYOCARDIAL INFARCTION - AN "UNCLEAR AREA"?}

Being a relatively rare disease, few data have been published regarding clinical studies on patients with autoimmune hemolytic anemia (AIHA) and AMI. Two cases have been reported, in which the acute coronary syndrome occurred as a complication of Evans Syndrome, which associates immune thrombocytopenic purpura and AIHA. ${ }^{30,31}$

In one of the above mentioned cases, the patient presented with STEMI and had undergone coronary stenting. The antiplatelet therapy following PCI was adjusted, and the patient had received single antiplatelet aspirin therapy when his thrombocyte level was lower than $50 \times 10^{9} / \mathrm{L}$, and no aspirin when his platelet count was less than $30 \times$ $10^{9} / \mathrm{L}$. Moreover, the patient had received a platelet transfusion when his platelet count was $<30 \times 10^{9} / \mathrm{L}^{31}$

A large Swedish study (2012), which retrospectively analyzed the connection between immune-mediated disorders including AIHA and atherosclerotic coronary heart disease (CHD), enrolled a total number of 336,479 patients admitted between 1987 and 2008 with immunemediated diseases. The study indicated a 3.17 (95\% CI 2.16-4.47) risk of CHD in AIHA patients during the first year after hospitalization. However, it should be mentioned that the established overall risk of CHD for immune-mediated disorders in this study was 2.92 (95\% CI $2.84-2.99) .^{32}$

\section{ACUTE CORONARY SYNDROME IS A SERIOUS CLINICAL MANIFESTATION IN SICKLE CELL ANEMIA}

Sickle cell disease (SCD) is a chronic hemolytic anemia, which leads to recurrent ischemic episodes resulting in a generalized progressive multi-organ dysfunction. SCD patients with AMI, diagnosed based on symptoms, ECG and elevated cardiac enzymes, often present with normal coronary arteries upon coronarography. The myocardial ischemia in SCD is caused by endothelial dysfunction, microvascular obstruction due to the pro-thrombotic state, and also by the systemic vasculopathy secondary to the bounding of nitric oxide to plasma hemoglobin (which is very high due to hemolysis). 33,34

An autopsy study (from 2012 to 2016) of 427 heart specimens from patients who had died suddenly, reported 12 cases with SCD. Upon reviewing the medical history of the deceased patients, only five patients presented with chest pain. The microscopic examination showed vessel congestion with sickle cells in all 12 cases, MI with coronary atherosclerosis in 41.66\%, MI with normal coronaries in $33.33 \%$ of cases, myocardial hypertrophy in $8.33 \%$ of cases, and media calcifications in $16.6 \%$ of patients. ${ }^{35}$

\section{CORONARY ARTERY THROMBOSIS IN PATIENTS WITH PAROXYSMAL NOCTURNAL HEMOGLOBINURIA}

Paroxysmal nocturnal haemoglobinuria $(\mathrm{PNH})$ is a rare disorder that causes intravascular hemolysis followed by hemoglobinuria, with a high risk of thrombosis. ${ }^{36}$ Thromboembolic events in PNH are caused by the activation of the $\mathrm{C} 5$ complement factor through hemoglobin release during hemolysis, leading to endothelial damage and subsequent intravascular thrombosis. On the other hand, nitric oxide depletion caused by circulating hemoglobin molecules leads to arterial thrombosis. By using C5 complement factor inhibitor as a therapeutic option, the thrombotic events are reduced, therefore complement and complement-mediated hemolysis play a major role in thrombosis in $\mathrm{PNH}$ patients. ${ }^{36}$ 
A review on a single Spanish center's forty years' experience found 56 patients with $\mathrm{PNH}$, with an average age of $38 \pm 17.7$ years at the time of diagnosis and a mean survival time of $11 \pm 12.09$ years following positive diagnosis. Arterial or venous thrombotic events occurred in 37 cases (66.07\%), from which only three caused acute coronary syndromes. ${ }^{37}$

A review by Ziakas et al. (2007) found 339 patients with PNH and thrombotic events, with a mean age of $34.5 \pm 13.7$ years. Arterial thrombosis mainly occurred at a coronary level that led to acute myocardial infarctions in young patients, mean age $35 \pm 13.7$ years, whereas in older patients the thrombosis caused strokes. The incidence of MI was relatively low ( $n=12 ; 3.31 \%$, RR: 20.53; 95\% CI: 4.42-95.28)..$^{38}$

Yu et al. (2016) sought to perform a comparative analysis on the clinical manifestations of PNH patients in Asia, Europe/America, by evaluating all retrospective studies on PNH published after 2000. They reported on 1,665 patients and found that the rate of PNH was significantly lower in Asia, and that Asian subjects had a more increased incidence of arterial thrombotic events in comparison with Western patients, who presented a higher incidence of abdominal venous thrombosis. Despite this, the total mortality rate was not significantly different between the two groups. ${ }^{39}$

\section{IS ACUTE CORONARY SYNDROME A COMMON APPEARANCE IN APLASTIC ANEMIA?}

Aplastic anemia is caused by bone marrow failure that leads to a decreased blood cell count on several lines. Acute coronary events in patients with aplastic anemia have a very low incidence, but there are a few cases cited in the literature.

A case of a 52-year-old patient with aplastic anemia with late stent thrombosis has been published in 2012 by Shin et al. ${ }^{0}$ The patient had undergone PCI with stent angioplasty on the left anterior descending artery one year before presentation. At presentation, the platelet count was $12,000 / \mu \mathrm{L}$, for which the patient had received platelet transfusion resulting in acute stent thrombosis. This case illustrates the increased risk correlated with platelet transfusion in patients with coronary stenting. $4^{0}$

\section{LEUKEMIA AND MYELODYSPLASTIC SYNDROME IN PATIENTS WITH ACS}

\section{ACUTE LEUKEMIA AND THE RISK OF DEVELOPING AN ACUTE CORONARY SYNDROME}

A literature search identified seven case reports of subjects with acute myeloid leukemia (AML) and acute coronary events. ${ }^{41-47}$
Two physiopathological pathways promote the formation of intravascular thrombi in AML. Firstly, hyperleukocitosis compromises tissue perfusion by changing blood rheology and altering microvascular circulation mostly in the central nervous system and respiratory system. The myocardium is affected if coronary atherosclerosis is present. ${ }^{47}$ Secondly, a hypercoagulability state, which is caused by the release of potent procoagulant factors from leukemic cells, can lead to the activation of the coagulation cascade, resulting in disseminated intravascular coagulation. ${ }^{44}$

\section{MYELODYSPLASTIC SYNDROME}

Myelodysplastic syndrome (MDS) is a group of myeloid neoplasms that affects older population more frequently, in which the bone marrow fails to produce blood cells, leading to cytopenia. MDS is a rare disease on its own, and even more rare in association with ACS, therefore there are very few literature data on the subject, mainly case reports.

A case report (2016) described a patient with acute myocardial infarction caused by thrombotic microangiopathy complicated with myelodysplastic syndrome. The patient presented with systemic microthrombosis including coronary artery involvement and pancytopenia caused by MDS, with deletion of the long arm of chromosome 20. Oral anticoagulation therapy was stopped because of hemorrhoidal bleeding, which required a blood transfusion. The recovery of the patient was successful without antiplatelet and anticoagulation therapy, which were avoided due to the low platelet count..$^{48}$

Oliva et al. (2011) performed a systematic analysis of the literature on anemia due to MDS and a negative cardiovascular prognosis. Their search revealed that despite the lack of studies on this topic, there seems to be a good relationship between low hemoglobin levels and cardiovascular morbidity and mortality, suggesting that anemia in MDS patients should be managed before requiring blood transfusions. ${ }^{49}$

\section{CHRONIC LYMPHOCYTIC LEUKEMIA AND ACS}

Increased leukocyte count, which can be the first manifestation of chronic lymphocytic leukemia (CLL), leads to a high risk of coronary artery disease (CAD) and it represents a negative prognostic factor for CAD. An increased white blood cell count has also been demonstrated to represent an independent risk factor for atherosclerosis. ${ }^{50}$ 
TABLE 1. Acute coronary syndrome in $A M L$ patients

\begin{tabular}{|c|c|c|c|c|c|c|c|c|}
\hline Altwegg et al. ${ }^{41}$ & male & 51 & 2010 & M3 & $2,200 / \mathrm{mm}^{3}$ & $85,000 / \mathrm{mm}^{3}$ & - & $\begin{array}{l}\text { AMI and intracoronary drug- } \\
\text { eluting-stent thrombosis }\end{array}$ \\
\hline Sargsyan et al. ${ }^{42}$ & male & 45 & - & - & $10,000 / \mathrm{mm}^{3}$ & - & - & AMI \\
\hline Ofran et al. 43 & female & 56 & 1993 & M1 & $316,000 / \mathrm{mm}^{3}$ & $35,000 / \mathrm{mm}^{3}$ & - & AMI \\
\hline Muñiz ${ }^{45}$ & male & 54 & - & M3 & $640 / \mathrm{mm}^{3}$ & $11,200 / \mathrm{mm}^{3}$ & - & AMI \\
\hline Colović et al. ${ }^{46}$ & male & 76 & - & - & $\begin{array}{c}\text { extreme } \\
\text { leukocytosis }\end{array}$ & - & $?$ & AMI and stroke \\
\hline Cohen et al. ${ }^{47}$ & male & 37 & 2012 & $\begin{array}{l}\text { MLL (lympho- } \\
\text { monoblastic) }\end{array}$ & $354,000 / \mathrm{mm}^{3}$ & $60,000 / \mathrm{mm}^{3}$ & - & $\begin{array}{l}\text { AMI and deep vein thrombo- } \\
\text { sis of the lower limb }\end{array}$ \\
\hline
\end{tabular}

A review on the effect of leukocytosis in patients with ischemic vascular disease included 350,000 patients from studies published between 1974 and 2005. The results showed a significant association between high white cell blood count and increased cardiovascular mortality and morbidity. Leukocytosis leads to an enhanced risk of acute thrombosis and stimulates the chronic atherosclerotic process, also causing microvascular occlusion. Initiating therapies that lower the leukocyte count may be appropriate in selected cases in order to improve prognosis, but hydroxyurea has leukemogenic potential, therefore its administration should be limited to high-risk elderly patients, for short time periods. ${ }^{51}$

A case report described an 83-year-old man diagnosed and treated with CLL, who presented acute myocardial infarction and died shortly after admission. The necropsy revealed myocardial infarction of the lateral wall of the left ventricle and severe atherosclerotic calcifications of the coronary arteries. Microscopic examination showed wall infiltration of the coronary arteries with leukemic cells, and also invasion of the atheromatous plaques with leukocytes, which could have contributed to plaque rupture and occurrence of the acute coronary event. ${ }^{52}$

\section{THE INCREASED RISK OF AMI IN SUBJECTS WITH HODGKIN \& NON-HODGKIN LYMPHOMA}

Anthony et al. (2007) followed 7,033 patients (62\% males) registered in the British National Lymphoma Investigation database from 1967 to 2000. During followup, 2,441 patients had died, of which $99.3 \%$ had a known cause of death. One-hundred sixty-six patients from the deceased group had died due to myocardial infarction. Their results suggested that Hodgkin lymphoma patients had a more increased risk of AMI compared to the general population, and that the relative risk of death from MI was more than two-fold higher (RR: 2.1, 95\% CI 2.5-2.9).

Within the first year after the initiation of therapy, the myocardial infarction mortality rate increased four-fold. From year one to year fourteen after treatment initiation, the relative risk of death was increased two-fold, from year 15 to 19 four-fold, and after 20 to 24 years of treatment, the mortality caused by MI was increased threefold compared to the general population. They concluded that the mortality risk from MI after the initiation of therapy for Hodgkin lymphoma remains high for the next 25 years, and the risk is directly correlated with supradiaphragmatic radiotherapy, antracycline and vincristine treatment. ${ }^{53}$

Similar results were shown by Galper et al. (2011) in a retrospective study that included 1,279 Hodgkin lymphoma patients that had been treated with mediastinal radiotherapy (RT) alone or in association with chemotherapy, with a follow-up period of 14.7 years. Coronary artery disease was diagnosed in 107 cases, the mean time from radiotherapy to CAD being 15.8 years. The incidence of CAD in these patients increases every 5 years after RT. Myocardial infarction had occurred in 76 cases, from which 19 were fatal. They concluded that the incidence of cardiovascular disease and cardiac procedures is higher 10 years or more after RT, thus suggesting that the effectiveness of screening for CVD is limited before 10 years following initial treatment for Hodgkin lymphoma. ${ }^{54}$

Aleman et al. (2007) sought to evaluate the long-term risk for CVD in 1,474 patients that had survived 5 years after being diagnosed and treated for Hodgkin lymphoma, between 1965 and 1995, with a mean follow-up of 18.7 years. From the study population, $28 \%$ of patients were given RT alone, 5\% chemotherapy (CT) alone, 38\% RT 
and CT without anthracyclines, and 29\% received RT and CT including anthracyclines. In total, 619 cardiovascular diseases had been diagnosed in 354 patients, from which 102 events were myocardial infarctions. Also, there was a higher number of angina pectoris and MI cases compared to the general population. The incidence of MI was significantly higher after 10 years following treatment. However, there were no significant differences in the rate of MI, angina pectoris and congestive heart failure between different treatment regimens. ${ }^{55}$

Four cases of non-Hodgkin lymphoma patients that presented with acute coronary syndromes were reported in the literature, in 2009, 2013, 2014, and 2015..$^{56-59}$ They presented with acute constrictive chest pain shortly after the administration of chemotherapy, and ECG and enzymatic changes were suggestive of AMI. They received different combinations of cytostatic treatment including rituximab-vincristine, cyclophosamide, prednison/rituximab-cyclophosphamide, doxorubicin, vincristine and prednisone/bendamustine and rituximab. Two of these cases presented with AMI after Rituximab administration. Generally, Rituximab, an anti-CD20 monoclonal antibody, is not cardiotoxic, but arrhythmias have been reported in association with its administration. MI secondary to treatment with Rituximab is caused by platelet activation, plaque rupture and vasoconstriction, especially in subjects with preexisting coronary atherosclerosis and vulnerable coronary plaques..$^{56-59}$

\section{RISK OF ACS IN PATIENTS WITH MULTIPLE MYELOMA (MM) AND MONOCLONAL GAMMOPATHY OF UNDETERMINED SIGNIFICANCE (MGUS)}

Kristinsson et al. (2010), using a Swedish database, assessed the risk of venous and arterial thrombosis in 18,627 individuals with multiple myeloma (MM) and 5,326 patients with monoclonal gammopathy of undetermined significance (MGUS). They concluded that MM as well as MGUS patients present a high risk of both arterial and venous thrombosis, with a higher incidence of venous thrombosis compared with arterial thrombosis. ${ }^{60}$

A prospective cohort study evaluating the risk of arterial thrombosis included 195 subjects with multiple myeloma ( $M M)$, who underwent chemotherapy followed by melphalan and autologous stem cell transplantation. From the study population, eleven patients $(5.6 \%)$ had developed arterial thrombotic events, having as risk factors arterial hypertension, tobacco use and increased levels of factor VIII. ${ }^{61}$
Two population-based studies were conducted in 2010 and 2016 to assess the risk of thrombosis in MM subjects. The results showed a higher risk of both venous and arterial thrombosis, which occurred mostly during chemotherapy induction, and when thalidomide and lenalidomide were used. Prophylaxis of the thrombosis in patients with MM is necessary and it can be achieved with aspirin, low-molecular-weight heparin and warfarin/acenocumarol. Thromboprophylaxis is recommended in all MM patients that do not present a high risk of bleeding. ${ }^{62,63}$

A case report (2010) highlighted the relationship between bortezomib treatment and ischemic heart disease. A 79-year-old patient diagnosed with MM, without any history of cardiovascular disease, presented with acute myocardial infarction during treatment with bortezomib. The patient underwent emergency coronary angioplasty with stent implantation and continued with the course of chemotherapy. Five days later the patient developed chest pain due to coronary spasm, which is a side effect of bortezomib therapy, due to endothelial dysfunction and impairment of nitric oxide production. ${ }^{64}$

\section{CONCLUSIONS}

Patients with previously diagnosed hematological disorders are at an increased risk for acute coronary syndromes, with a higher risk of thrombosis or bleeding, depending on the underlying hemopathy. Leukemia and myelodysplastic syndrome lead to an increased inflammatory status that causes coronary plaque disruption and infiltration of the vessel wall, leading to acute thrombosis and myocardial infarction. On the other hand, the presence of blood clotting disorders, including thrombopathies, thrombocytopenia and conditions that impair various coagulation factors, can lead to a high hemorrhagic risk, thus affecting the outcome of patients that undergo percutaneous coronary interventions or coronary artery bypass grafting. Furthermore, patients with a high hemorrhagic risk due to blood clotting disorders should receive bare-metal stents that require a shorter period of dual antiplatelet treatment.

Multiple myeloma leads to a pro-thrombotic state that causes both arterial and venous thrombosis. Paroxysmal nocturnal hemoglobinuria leads to a high risk of thrombosis that may lead to acute coronary events. Patients with lymphoma present a late risk of developing cardiovascular disease due to radiotherapy and chemotherapy, therefore an efficient control of the cardiovascular risk factors might lead to a risk reduction. 


\section{CONFLICT OF INTEREST}

Nothing to declare.

\section{ACKNOWLEDGEMENT}

This research was supported by the Cardio Med Medical Center, project no. CAM/2015/RD/19.

\section{REFERENCES}

1. Massberg S, Schulz C, Gawaz M. Role of platelets in the pathophysiology of acute coronary syndrome. Semin Vasc Med. 2003;3:147-182. doi: 10.1055/s-2003-40673.

2. Balasubramaniyam N, Kolte D, Palaniswamy C, et al. Predictors of in-hospital mortality and acute myocardial infarction in thrombotic thrombocytopenic purpura. Am J Med. 2013;126:1016.e1-7. doi: 10.1016/j.amjmed.2013.03.021.

3. Gandhi K, Aronow WS, Desai $\mathrm{H}$, et al. Cardiovascular Manifestations in Patients With Thrombotic Thrombocytopenic Purpura: A Single-center Experience. Clin Cardiol. 2010 Apr;33(4):213-6. doi: 10.1002/clc.20731.

4. Wahla AS, Ruiz J, Noureddine N, Upadhya B, Sane DC, Owen J. Myocardial infarction in thrombotic thrombocytopenic purpura: a single-center experience and literature review. Eur J Haematol. 2008;81:311-316. doi: 10.1111/j.16000609.2008.01112.x.

5. Frutcher O, Blich M, Jacob G. Fatal acute myocardial infarction during severe thrombocytopenic purpura. Am J Med Sci. 2002;323:279-280.

6. Torbey E, Yacoub H, McCord D, Lafferty J. Two Cases and Review of the Literature: Primary Percutaneous Angiography and Antiplatelet Management in Patients with Immune Thrombocytopenic Purpura. ISRN Hematology. 2013;2013:174659. doi: 10.1155/2013/174659.

7. Russo A, Cannizzo M, Ghetti G, Branzi A. Idiopathic thrombocytopenic purpura and coronary artery disease: comparison between coronary artery bypass grafting and percutaneous coronary intervention. Interact Cardiovasc Thorac Surg. 2011;13:153-157. doi: 10.1510/icvts.2011.271296.

8. Fujino S, Niwa S, Fujioka K, et al. Primary Percutaneous Coronary Intervention by a Stentless Technique for Acute Myocardial Infarction with Idiopathic Thrombocytopenic Purpura: A Case Report and Review of the Literature. Intern Med. 2016;55:147-152. doi: 10.2169/internalmedicine.55.4544.

9. Shen F, Nfor T, Bajwa T. Recurrent acute myocardial infarction in patients with immune thrombocytopenic purpura. J Patient Cent Res Rev. 2014;1:41-45. doi: 10.17294/2330-0698.1010.

10. Sakai H, Goto S, Kim JY, et al. Plasma concentration of von Willebrand factor in acute myocardial infarction. Thromb Haemost. 2000;84:204-209.

11. Sonneveld MA, Cheng JM, Oemrawsingh RM, et al. Von Willebrand factor in relation to coronary plaque characteristics and cardiovascular outcome. Thromb Haemost. 2015;113:577584. doi: 10.1160/TH14-07-0589.

12. Lim MY, Pruthi RK. Outcomes of management of acute coronary syndrome in patients with congenital bleeding disorders: a single center experience and review of the literature. Thromb Res. 2012;130:316-322. doi: 10.1016/j.thromres.2012.02.050.
13. Rathore S, Deleon D, Akram H, Sane D, Ball T. Percutaneous Coronary Intervention and the Management of Acute Coronary Syndromes in Patients With von Willebrand Disease. J Invasive Cardiol. 2013;25:E81-E86.

14. Rana MA, Vutukuri NM, Acharya MM, Akkus NI. Acute coronary syndrome and coronary intervention in a patient with type $2 \mathrm{M}$ von Willebrand disease. Int J Cardiol. 2014;176:484-485. doi: 10.1016/j.ijcard.2014.06.066.

15. Martin K, Key NS. How I treat patients with inherited bleeding disorders who need anticoagulant therapy. Blood. 2016;128:178-184. doi: 10.1182/blood-2015-12-635094.

16. Zawilska K, Podolak-Dawidziak M. Therapeutic problems in elderly patients with hemophilia. Pol Arch Med Wewn. 2012;122:567-576.

17. Staritz P, de Moerloose P, Schutgens R, Dolan G; ADVANCE Working Group. Applicability of the European Society of Cardiology guidelines on management of acute coronary syndromes to people with haemophilia. Haemophilia. 2013;19:833-840. doi: 10.1111/hae.12189.

18. Fefer P, Gannot S, Lubetsky A. Percutaneous coronary intervention in patients with haemophilia presenting with acute coronary syndrome: an interventional dilemma: case series, review of the literature, and tips for management. J Thromb Thrombolysis. 2013;35:271-278. doi: 10.1007/s11239012-0802-y.

19. Minuk L, Jackson S, Iorio A. Cardiovascular disease (CVD) in Canadians with haemophilia: Age-Related CVD in Haemophilia Epidemiological Research (ARCHER study). Haemophilia. 2015;21:736-741. doi: 10.1111/hae.12768.

20. Fransen van de Putte, Fischer K, Pulles AE, et al. Non-fatal cardiovascular disease,malignancies, and other co-morbidity in adult haemophilia patients. Thromb Res. 2012;130:157-162. doi: 10.1016/j.thromres.2011.12.012.

21. Fogarty PF, Mancuso ME, Kasthuri R, et al. Presentation and management of acute coronary syndromes among adult persons with haemophilia: results of an international, retrospective, 10-year survey. Haemophilia. 2015;21:589-597. doi: 10.1111/hae.12652.

22. Provan D, Baglin T, Dokal I. Oxford Handbook of Clinical Haematology. 4th ed. Oxford University Press;2015. p. 258261.

23. Landolfi R, Marchioli R, Kutti J, et al. Efficacy and Safety of Low-Dose Aspirin in Polycythemia Vera. N Engl J Med. 2004;350:114-124. doi: 10.1056/NEJMoa035572

24. Barbui T, Finazzi G, Falanga A. Myeloproliferative neoplasms and thrombosis. Blood. 2013;122:2176-2184. doi: 10.1182/ blood-2013-03-460154.

25. Tortorella G, Calzolari M, Tieghi A, Muià N, Piccin A, Gugliotta L. Acute coronary syndrome (ACS) in patients with essential thrombocytemia (ET). What is the best treatment. International Journal of Cardiology 2016;203:225-227. http:// dx.doi.org/10.1016/j.ijcard.2015.10.043.

26. De Stefano V, Za T, Rossi E, et al. Recurrent thrombosis in patients with polycythemia vera and essential thrombocythemia: incidence, risk factors, and effect of treatments. Haematologica. 2008;93:372-380. doi: 10.3324/ haematol.12053.

27. Ziakas PD. Effect of JAK2 V617F On Thrombotic Risk In Patients With Essential Thrombocytemia: Measuring the Uncertain. Haematologica. 2008;93:1412-1414. doi: 10.3324/ haematol.12970. 
28. Lee HS, Park LC, Lee EM, et al. Incidence rates and risk factors for vascular events in patients with essential thrombocythemia: a multicenter study from Korea. Clin Lymphoma Myeloma Leuk. 2012;12:70-75. doi: 10.1016/j.clml.2011.10.002.

29. Pósfai É, Marton I, Borbényi Z, Nemes A. Myocardial infarction as a thrombotic complication of essential thrombocythemia and polycythemia vera. Anatol J Cardiol. 2016;16:397-402. doi: 10.14744/AnatolJCardiol.2015.6125.

30. Zhang $\mathrm{Y}$, Zheng $\mathrm{K}$, Zheng $\mathrm{M}$, Liu Q Meng L. The positive therapeutic effect in a patient of Evans syndrome combined with acute myocardial infarction. Int $\mathrm{J}$ Clin Exp Med. 2015;8:9590-9594.

31. Kizilirmak F, Demir GG, Cakal B, Bekoz HS, Olgun FE. Evans syndrome with non-ST segment elevation myocardial infarction complicated by hemopericardium. Indian Heart J. 2016;68(Suppl2):S280-S283. doi: 10.1016/j.ihj.2015.11.041.

32. Zöller B, Li X, Sundquist J, Sundquist K. Risk of Subsequent Coronary Heart Disease in Patients Hospitalized for ImmuneMediated Diseases: A Nationwide Follow-Up Study from Sweden. PLoS One. 2012;7:e33442. doi: 10.1371/journal. pone.0033442.

33. Assanasen C, Quinton RA, Buchanan GR. Acute myocardial infarction in sickle cell anemia. J Pediatr Hematol Oncol. 2003;25:978-981.

34. Gladwin MT, Sachdev V. Cardiovascular Abnormalities in Sickle Cell Disease. J Am Coll Cardiol. 2012;59:1123-1133. doi: 10.1016/j.jacc.2011.10.900.

35. BhaskarV, Joshi C. Effect of SickleCell Disease on Cardiovascular System: A 4.5 Years Autopsy Study Conducted in a Tertiary Care Center of Central India. International Journal of Scientific Study 2016;4:188-192. doi: 10.17354/ijss/2016/404.

36. van Bijnen STA, van Heerde WL, Muus P. Mechanisms and clinical implications of thrombosis in paroxysmal nocturnal hemoglobinuria J Thromb Haemost. 2012;10:1-10. doi: 10.1111/j.1538-7836.2011.04562.x.

37. Muñoz-Linares C, Ojeda E, Forés R, et al. Paroxysmal nocturnal hemoglobinuria: a single Spanish center's experience over the last 40 year. Eur J Haematol. 2014;93:309-319. doi: 10.1111/ ejh.12346.

38. Ziakas PD, Poulou LS, Rokas GI, Bartzoudis D, Voulgarelis M. Thrombosis in paroxysmal nocturnal hemoglobinuria: sites, risks, outcome. An overview. J Thromb Haemost. 2007;5:642645. doi: 10.1111/j.1538-7836.2007.02379.x.

39. Yu F, Du Y, Han B. A comparative analysis of clinical characteristics of patients with paroxysmal nocturnal hemoglobinuria between Asia and Europe/America. Int J Hematol. 2016;103:649-654. doi: 10.1007/s12185-016-1995-1.

40. Shin HS, Kang TS. A Case of Late Stent Thrombosis Following Platelet Transfusion in a Patient With Aplastic Anemia. Korean Circ J. 2012;42:54-57. doi: 10.4070/kcj.2012.42.1.54.

41. Altwegg SC, Altwegg LA, Maier W. Intracoronary thrombus with tissue factor expression heralding acute promyelocytic leukaemia. Eur Heart J. 2007;28:2731. doi: 10.1093/eurheartj/ ehm216.

42. Sargsyan Z, Higgins C, Alexandrescu S, Ott DA, Jain SK. Acute Promyelocytic Leukemia as a Cause of Intracoronary DrugEluting-Stent Thrombosis. Tex Heart Inst J. 2012;39:416-419.

43. Ofran Y, Tallman MS, Rowe JM. How I treat acute myeloid leukemia presenting with preexisting comorbidities. Blood. 2016;128:488-496. doi: 10.1182/blood-2016-01-635060.
44. CahillTJ, ChowdhuryO, Myerson SG, etal.Myocardial Infarction With Intracardiac Thrombosis as the Presentation of Acute Promyelocytic Leukemia. Circulation. 2011;123:e370-e372. doi: 10.1161/CIRCULATIONAHA.110.986208.

45. Muñiz AE. Myocardial infarction and stroke as the presenting symptoms of acute myeloid leukemia. J Emerg Med. 2012;42:651-654. doi: 10.1016/j.jemermed.2009.04.061.

46. Colović N, Bogdanović A, Virijević M, Vidović A, Tomin D. Acute Myocardial Infarction during Induction Chemotherapy for Acute MLL t(4;11) Leukemia with Lineage Switch and Extreme Leukocytosis. Srp Arh Celok Lek. 2015;143:734-738.

47. Cohen Y, Amir G, Da'as N, Gillis S, Rund D, Polliack A. Acute Myocardial Infarction as the Presenting Symptom of Acute Myeloblastic Leukemia With Extreme Hyperleukocytosis. Am J Hematol. 2002;71:47-49. doi: 10.1002/ajh.10155.

48. Oshima T, Ikutomi $\mathrm{M}$, Shinohara $\mathrm{H}$, et al. Acute Myocardial Infarction Caused by Thrombotic Microangiopathy Complicated With Myelodysplastic Syndrome. International Heart Journal. 2016;5:634-636. http://doi.org/10.1536/ihj.16-100.

49. Oliva EN, Schey C, Hutchings AS. A review of anemia as a cardiovascular risk factor in patients with myelodysplastic syndromes. American Journal of Blood Research. 2011;1:160166.

50. Madjid M, Awan I, Willerson JT, Casscells SW. Leukocyte Count and Coronary Heart Disease. Implications for Risk Assessment. J Am Coll Cardiol. 2004;44:1945-1956. doi: 10.1016/j.jacc.2004.07.056

51. Coller BS. Leukocytosis and ischemic vascular disease morbidity and mortality: is it time to intervene? Arterioscler Thromb Vasc Biol. 2005;25:658-670. doi: 10.1161/01. ATV.0000156877.94472.a5.

52. Assiri AH, Lambda M, Veinot JP. Chronic lymphocytic leukemia involving the coronary arteries with accompanying acute myocardial infarction. Cardiovasc Pathol. 2005;14:324326. doi: 10.1016/j.carpath.2005.07.006.

53. Swerdlow AJ, Higgins $C D$, Smith $P$, et al. Myocardial Infarction Mortality Risk After Treatment for Hodgkin Disease: A Collaborative British Cohort Study. J Natl Cancer Inst. 2007;99:206-214. doi: 10.1093/jnci/djk029.

54. Galper SL, Yu JB, Mauch PM, et. al. Clinically significant cardiac disease in patients with Hodgkin lymphoma treated with mediastinal irradiation. Blood. 2011;117:412-418. doi: 10.1182/blood-2010-06-291328.

55. Aleman BM, van den Belt-Dusebout AW, De Bruin ML, et al. Late cardiotoxicity after treatment for Hodgkin lymphoma. Blood. 2007;109:1878-1886. doi: 10.1182/blood-2006-07-034405.

56. Roy A, Khanna N, Senguttuvan NB. Rituximab-vincristine chemotherapy-induced acute anterior wall myocardial infarction with cardiogenic shock. Tex Heart Inst J. 2014;41:8082. doi: 10.14503/THIJ-12-2853.

57. Keswani AN, Williams C, Fuloria J, Polin NM, Jahangir E. Rituximab-Induced Acute ST Elevation Myocardial Infarction. Ochsner J. 2015;15:187-190.

58. Gogia A, Khurana S, Paramanik R. Acute Myocardial Infarction after First Dose of Rituximab Infusion. Turkish Journal of Hematology. 2014;31:95-96. doi:10.4274/Tjh.2013.0247.

59. Rathi S, Shakir F, Sech C, Lazzara R. Non-Hodgkin Lymphoma Causing Acute Myocardial Infarction and Tachyarrhythmia Am J Cardiol. 2009;104:450-452. doi: 10.1016/j.amjcard.2009. 03.065 . 
60. Kristinsson SY, Pfeiffer RM, Björkholm M, et al. Arterial and venous thrombosis in monoclonal gammopathy of undetermined significance and multiple myeloma: a population-based study. Blood. 2010;115:4991-4998. doi: 10.1182/blood-2009-11-252072.

61. Libourel EJ, Sonneveld P, van der Holt B, de Maat MP, Leebeek FW. High incidence of arterial thrombosis in young patients treated for multiple myeloma: results of a prospective cohort study. Blood. 2010;116:22-26. doi: 10.1182/ blood-2009-12-257519.

62. Kristinsson SY. Thrombosis in multiple myeloma. Hematology
Am Soc Hematol Educ Program. 2010;2010:437-444. doi: 10.1182/asheducation-2010.1.437.

63. Weijuan L, Frank C, Daniel L, et al. Cardiovascular Complications of Novel Multiple Myeloma Treatments. Circulation. 2016;133:908-912. https://doi.org/10.1161/ CIRCULATIONAHA.115.018351.

64. Takamatsu H, Yamashita T, Kotani T, Sawazaki A, Okumura H, Nakao S. Ischemic heart disease associated with bortezomib treatment combined with dexamethasone in a patient with multiple myeloma. Int J Hematol. 2010;91:903-906. doi: 10.1007/s12185-010-0586-9. 